\title{
Calcipotriol/betamethasone dipropionate aerosol foam for the treatment of psoriasis vulgaris: case series and review of the literature
}

This article was published in the following Dove Press journal:

Clinical, Cosmetic and Investigational Dermatology

\author{
Andreas Pinter ${ }^{1}$ \\ Henrik Thormann² \\ Flavia Angeletti' \\ Ahmad Jalili ${ }^{3}$ \\ 'Department of Dermatology, \\ Venereology, and Allergology, \\ University Hospital Frankfurt am \\ Main, Frankfurt am Main, Germany; \\ ${ }^{2}$ Dermatology Clinic, Vejle, Denmark; \\ ${ }^{3}$ Department of Dermatology, \\ Bürgenstock Medical Center, \\ Obbürgen, Switzerland
}

\begin{abstract}
An aerosol foam formulation of a once-daily, fixed-dose combination of a synthetic vitamin $\mathrm{D}_{3}$ analog/synthetic corticosteroid (calcipotriol [Cal] $50 \mu \mathrm{g} / \mathrm{g}$ and betamethasone dipropionate [BD] $0.5 \mathrm{mg} / \mathrm{g}$ ) has recently been introduced for the topical treatment of plaque psoriasis in adults. Data from several sources - randomized controlled trials, case reports (as highlighted in this review), and real-world evidence (RWE) - underscore the considerable and rapid clinical response, effectiveness, and favorable safety and tolerability of Cal/BD aerosol foam in mild-tomoderate psoriatic patients previously treated with class 3 or 4 topical corticosteroids, in patients unsatisfied with ongoing phototherapy in combination with topical therapy and in patients with moderate-to-severe psoriasis. In addition, our case series, considered together with other RWE, highlights that $\mathrm{Cal} / \mathrm{BD}$ aerosol foam is more effective and with greater levels of patient preference and acceptability than comparator preparations. Thus, $\mathrm{Cal} / \mathrm{BD}$ aerosol foam offers several treatment advantages, including relief of itch, and is an appropriate first-line topical therapy for consideration in patients with psoriasis of any severity.
\end{abstract}

Keywords: aerosol, betamethasone dipropionate, calcipotriol, psoriasis

\section{Introduction}

Psoriasis is a chronic, immune-mediated inflammatory disorder with a significant detrimental impact on health-related quality of life (HRQoL), ${ }^{1-4}$ similar to the negative effect of other chronic conditions (eg, diabetes) on HRQoL. ${ }^{5}$ Overall, the prevalence of psoriasis has been estimated to be about $2 \%$ of the population, ${ }^{6-8}$ although this figure may vary markedly between geographic regions and ethnic groups. A recent, population-based survey of more than 20,000 adults in France revealed a psoriasis prevalence of $4.42 \%{ }^{9}$

Besides its deleterious effect on HRQoL, psoriasis presents specific, major burdens to patients such as troublesome itch, which is a significant symptom in many patients. ${ }^{3}$ In addition, society and health care payors are affected due to the large socioeconomic burden of psoriasis: this includes loss of work productivity ${ }^{8,10-12}$ and treatment costs. In particular, treatment costs for biologic agents including biosimilars are significantly higher than those with topical therapies. ${ }^{8,10,13}$ The emotional burden to patients, and the burden posed by common comorbidities, such as psoriatic arthritis, Crohn's disease, cardiovascular disorders including metabolic syndrome, and depression, should also not be overlooked. ${ }^{14,15}$

Traditional treatments for psoriasis comprise topical therapies, most frequently corticosteroids and/or vitamin $\mathrm{D}_{3}$ analogs, ${ }^{7,16}$ phototherapy (eg, ultraviolet B [UVB]),
Correspondence: Andreas Pinter Department of Dermatology, Venereology and Allergology, University Hospital Frankfurt am Main, TheodorStern-Kai 7, 60590 Frankfurt am Main, Germany

Tel +49696301 54l8

Email andreas.pinter@kgu.de 
photochemotherapy (eg, psoralen plus ultraviolet A [PUVA]), and systemic therapy (eg, methotrexate and fumaric acid esters)..$^{6,14,17-19}$ In some instances, these options, especially topical therapies, may be associated with a poor efficacy: tolerability ratio, poor cosmetic acceptability, and the potential for reduced adherence. ${ }^{19}$ However, most patients with psoriasis still use traditional treatments, ${ }^{14}$ and as most patients have mild-to-moderate disease $(<10 \%$ body surface area [BSA] affected), topical agents with a high efficacy:safety ratio are used widely. ${ }^{6,20}$ For patients with more extensive disease, topical agents can be used as adjunctive therapy to phototherapy, systemic, or biologic agents. ${ }^{6,7}$

Recently, a foam formulation of a once-daily, fixeddose combination (FDC) of a synthetic vitamin $\mathrm{D}_{3}$ analog/ synthetic corticosteroid (calcipotriol [Cal] $50 \mu \mathrm{g} / \mathrm{g}$ and betamethasone dipropionate [BD] $0.5 \mathrm{mg} / \mathrm{g}$ [Enstilar ${ }^{\circledR}$ \{calcipotriene and betamethasone dipropionate \}; Leo Pharma $\mathrm{GmbH}$, Frankfurt, Germany]) was introduced for the topical treatment of plaque psoriasis in adults. This alcohol-free, aerosol foam formulation, in which the active ingredients are dissolved in a mixture of volatile propellants (butane and dimethyl ether) to form a stable, supersaturated solution, is associated with enhanced skin penetration/increased bioavailability, greater efficacy, improved patient satisfaction, and the potential for greater patient adherence relative to comparator ointment and gel preparations. ${ }^{4,19}$

In several studies, treatment with $\mathrm{Cal} / \mathrm{BD}$ aerosol foam produced a significantly greater modified Psoriasis Area Severity Index 75 (mPASI75) response rate and a significantly better Dermatology Life-Quality Index (DLQI) score than a comparator $\mathrm{Cal} / \mathrm{BD}$ gel formulation; ${ }^{21}$ significantly better total clinical scores (ie, scores for the sum of erythema, scaling, and lesional thickness) than comparator $\mathrm{Cal} / \mathrm{BD}$ ointment, BD ointment, BD foam, and foam vehicle in Phase II studies; ${ }^{22,23}$ and significantly greater treatment success and mPASI75 response rates than with $\mathrm{Cal} / \mathrm{BD}$ gel in the Phase III PSO-ABLE study. ${ }^{24}$

$\mathrm{Cal} / \mathrm{BD}$ aerosol foam also demonstrated a significantly greater treatment success rate, mean mPASI score, and itch relief and a significantly improved $H R Q o L$, relative to vehicle in the Phase III PSO-FAST trial. ${ }^{5,25}$ A pooled analysis of Phase II/III data for 1,104 patients revealed that Cal/BD aerosol foam was significantly more effective than the FDC ointment and the combination constituents, in producing faster and greater decreases in disease severity, and in providing fast, effective antipruritic activity; ${ }^{26}$ other authors reported that $\mathrm{Cal} / \mathrm{BD}$ aerosol foam produced greater improvements in itch-related sleep loss than its comparators. ${ }^{27}$
As an important addition to the abovementioned clinical trial data, the purpose of the current review is to explore real-world evidence (RWE) for Cal/BD aerosol foam from a collection of clinical cases involving patients with psoriasis. Patients provided written informed consent for the case details and any accompanying images to be published.

\section{Clinical cases}

Case 1: Cal/BD aerosol foam in mild-to-moderate psoriasis after previous treatment with a class 3 topical corticosteroid with vitamin $\mathrm{D}_{3}$ analog

A 72-year-old male had had plaque psoriasis for 15 years. He had classic psoriasis-related symptoms and was receiving tamsulosin $0.4 \mathrm{mg} /$ day for benign prostatic hyperplasia. $\mathrm{He}$ had previously been treated with topical Cal $50 \mu \mathrm{g} / \mathrm{g}$ and betamethasone $0.5 \mathrm{mg} / \mathrm{g}$ ointment (2009-2010), methotrexate (2009-2013), and ustekinumab (2015-2017).

Physical examination revealed recalcitrant psoriasis, principally on the lower trunk and gluteal regions (Figure 1A). Psoriasis Area Severity Index (PASI) score at presentation was 5.5, and in February 2018, the patient started treatment with daily application of $\mathrm{Cal} / \mathrm{BD}$ aerosol foam, which was continued for 4 weeks.

After 4 weeks' treatment, the psoriatic lesions had markedly improved (Figure 1B) and PASI score had decreased to 1.5. The patient was very satisfied with treatment, and the need for systemic therapy was avoided.

Case 2: Cal/BD aerosol foam in mild-to-moderate psoriasis after a long history of systemic therapy, PUVA, and topical drugs

A 72-year-old male had a 25-year history of psoriasis. He had classic psoriasis-related symptoms and was receiving atorvastatin for hypercholesterolemia, losartan and bendroflumethiazide for hypertension, and prophylactic clopidogrel for stroke. He had previously received 80 sessions of PUVA, eight courses of UVB, many years of acitretin therapy, and various topical treatments, including $\mathrm{Cal} /$ betamethasone and clobetasol. Acitretin therapy was stopped in March 2016, with the hope of controlling the psoriasis without systemic therapy. The patient was keen to try a new treatment.

Physical examination at presentation revealed recalcitrant psoriasis on the backs of the hands (Figure 2A), buttocks, and thigh. The patient was particularly troubled by the psoriasis on the back of his hands, which had shown no improvement, even during acitretin treatment. PASI score at presentation was 6.2, and in April 2017, the patient started treatment with daily application of $\mathrm{Cal} / \mathrm{BD}$ aerosol foam, which was continued for 4 weeks. 
A
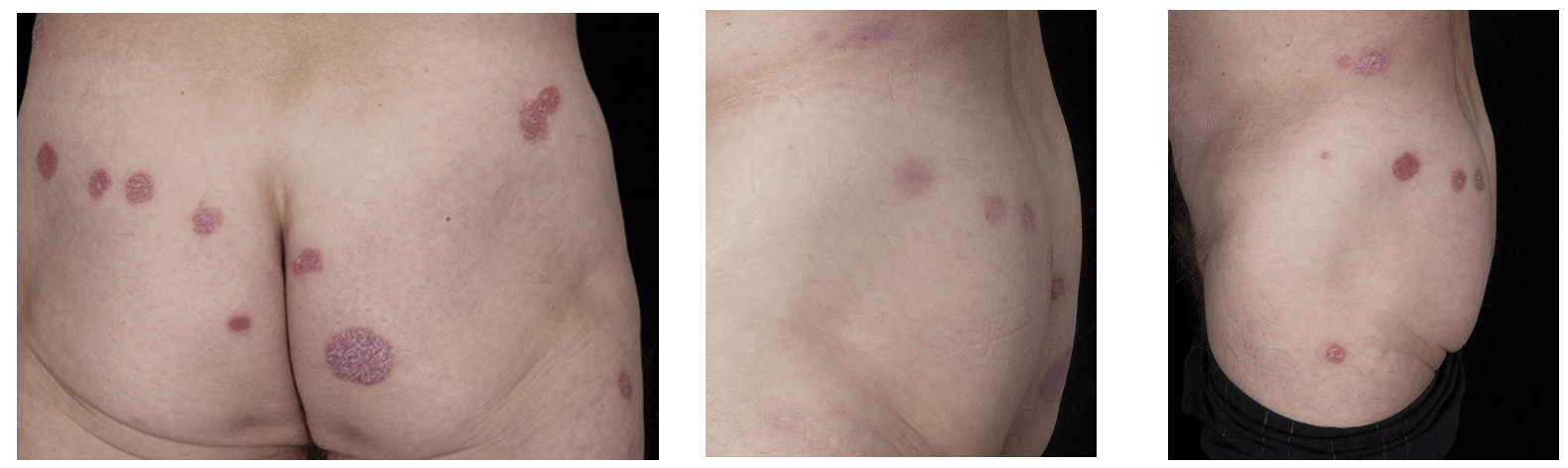

B
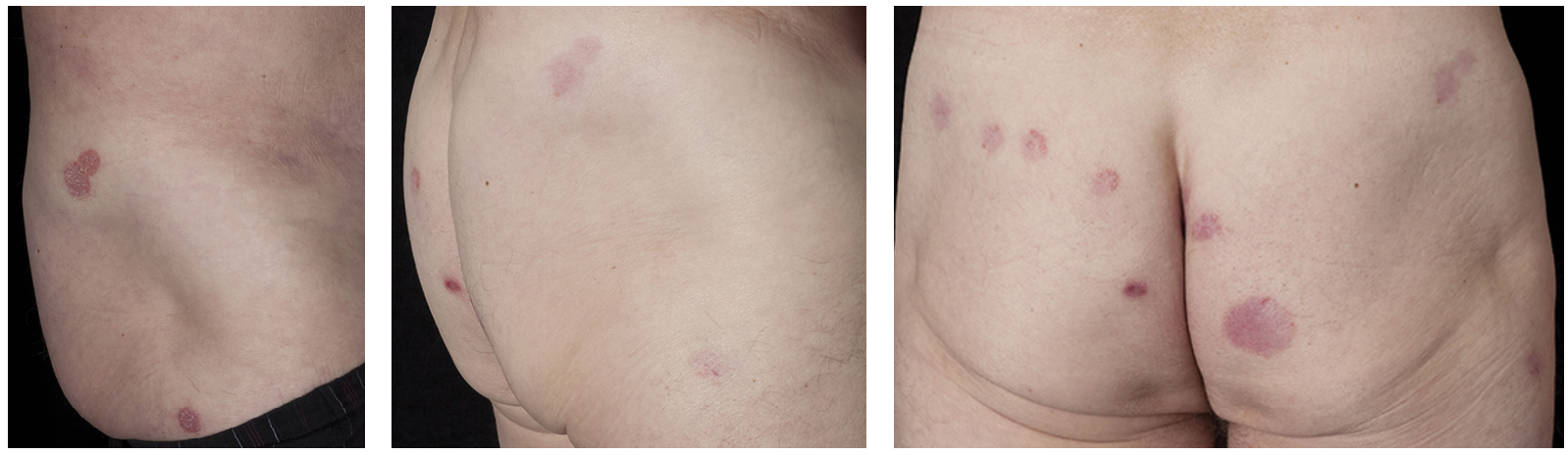

Figure I (A) Recalcitrant psoriasis on the lower trunk and gluteal regions of a 72-year-old male before treatment with Cal/BD aerosol foam. (B) Psoriatic lesions after 4 weeks' treatment with Cal/BD aerosol foam.

Abbreviations: $\mathrm{BD}$, betamethasone dipropionate; Cal, calcipotriol.

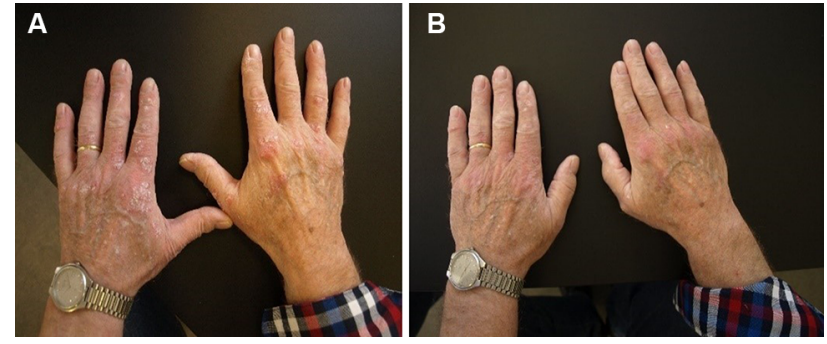

Figure 2 (A) Recalcitrant psoriasis on the backs of hands in a 78-year-old male before treatment with Cal/BD aerosol foam. (B) Psoriatic lesions after 4 weeks' treatment with $\mathrm{Cal} / \mathrm{BD}$ aerosol foam.

Abbreviations: $\mathrm{BD}$, betamethasone dipropionate; Cal, calcipotriol.

After 4 weeks' treatment, the psoriatic lesions had markedly improved (Figure 2B) and PASI score had decreased to 2.0. The patient was very satisfied with $\mathrm{Cal} / \mathrm{BD}$ aerosol foam, with the overall perception of particular efficacy for psoriasis on the back of his hands and no requirement for systemic therapy.

Case 3: $\mathrm{Cal} / \mathrm{BD}$ aerosol foam after previous treatment with class 4 topical corticosteroids
A 71-year-old male had a history of psoriasis, which had originally been diagnosed at the age of 30 years; however, throughout his life, the patient had also experienced remissions. Previous treatment had included various topical medications, such as mometasone furoate and clobetasol ointments, and narrowband UVB. The patient was receiving atorvastatin for hypercholesterolemia and omeprazole for dyspepsia.

Physical examination at presentation revealed hyperkeratotic psoriatic plaques on the legs and elbows, and the patient was especially troubled by psoriasis on the anterior legs (Figure 3A). PASI score at presentation was 7.2, and the patient started treatment with once-daily application of $\mathrm{Cal} /$ $\mathrm{BD}$ aerosol foam for 4 weeks.

After 4 weeks of treatment, the patient's psoriasis was less distinctive and less keratotic (Figure 3B), PASI score had decreased to 3.2 , and the patient was satisfied with the treatment outcome.

Case 4: An unsatisfied patient with a long history of using different topical therapies who switched to cal/BD aerosol foam 

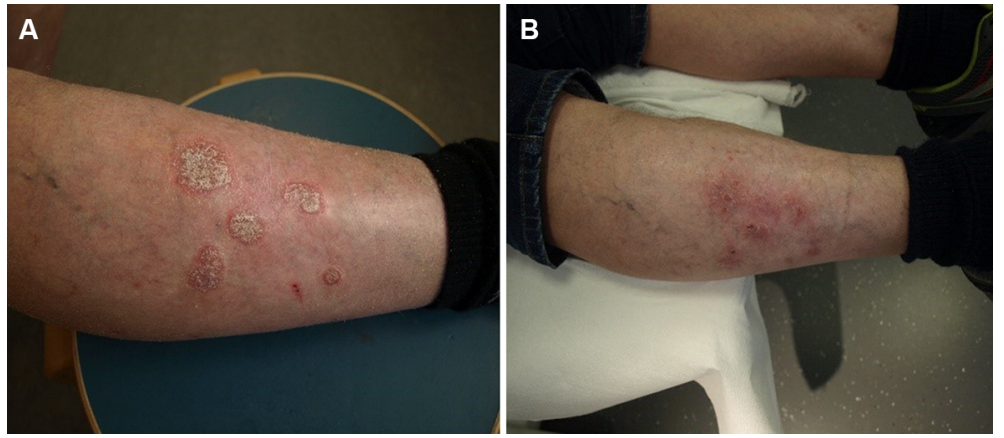

Figure 3 (A) Hyperkeratotic psoriasis on the anterior legs in a 7I-year-old male before treatment with Cal/BD aerosol foam. (B) Psoriatic lesions after 4 weeks' treatment with $\mathrm{Cal} / \mathrm{BD}$ aerosol foam.

Abbreviations: BD, betamethasone dipropionate; Cal, calcipotriol.

A 35-year-old male had experienced chronic recurrent psoriasis since early adulthood but without attendant joint pain. Previous treatment had included systemic therapy with fumaric acid esters a few years earlier, but this had to be discontinued because of tolerability issues. The patient had used several topical treatments, such as mometasone and betamethasone ointments, and various skin care preparations, but without success. Most recently, the patient had used topical $\mathrm{Cal} /$ betamethasone ointment once daily, but no significant skin improvement was attained. The patient was also dissatisfied with the fatty consistency of the ointment. He had reported no significant previous illnesses, other than mild allergic rhinitis and lipomatosis.

Physical examination at presentation revealed classic psoriatic plaques, each about $3-4 \mathrm{~cm}$ in diameter, on the elbows and knees, and on the posterior thigh (Figure 4A). PASI score at presentation was 4.8 , BSA involvement was $5 \%$, and the patient started treatment with once-daily application of $\mathrm{Cal} /$ $\mathrm{BD}$ aerosol foam.

After only 1 week of $\mathrm{Cal} / \mathrm{BD}$ application, reddening and infiltration of the plaques had significantly decreased (Figure 4B); pruritus had also completely subsided within the first week of treatment. After 4 weeks' application, most of the plaques had completely healed and existing residual lesions showed only minimal erythema without signs of infiltration or desquamation. The PASI score had decreased to 0.8. The patient was satisfied with $\mathrm{Cal} / \mathrm{BD}$ aerosol foam treatment, particularly the fast retraction of the foam.

Case 5: $\mathrm{Cal} / \mathrm{BD}$ aerosol foam in moderate-to-severe psoriasis after previous treatment with oral systemic therapy

A 56-year-old male had had psoriasis for 2 years. A family history was evident, as the patient's father also had psoriasis. The patient's PASI score was 12, DLQI score was 14, and the patient had approximately 13\% BSA affected (Figure 5A).
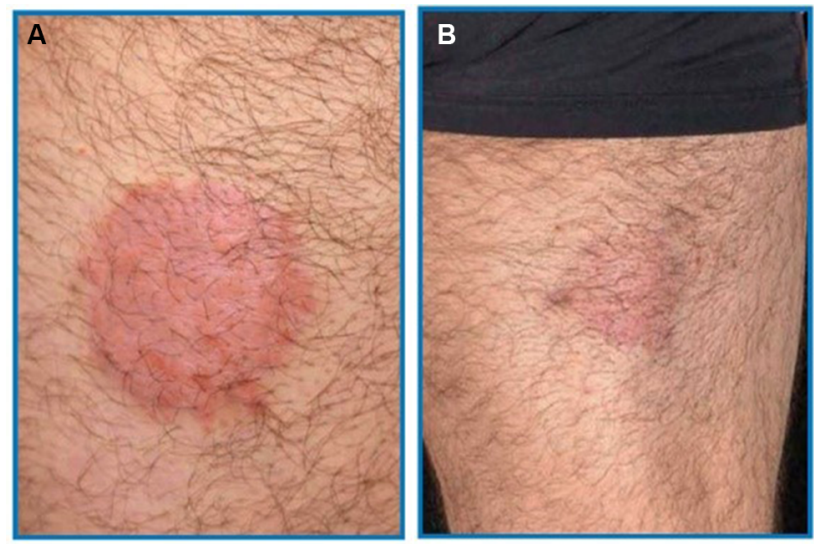

Figure 4 (A) Classic erythematosquamous plaque on the posterior thigh in a 35-year-old male before treatment with Cal/BD aerosol foam. (B) Psoriatic lesion after 4 weeks' treatment with Cal/BD aerosol foam.

Abbreviations: BD, betamethasone dipropionate; Cal, calcipotriol.

Previously, the patient had been treated unsuccessfully with topical corticosteroids, UVB phototherapy, and methotrexate.

Because PASI and BSA scores were $>10$, and previous systemic therapy with methotrexate was unsuccessful, the option of biologic therapy was introduced to, and discussed thoroughly with, the patient. Consequently, biologic drug prescreening (chest X-ray, QuantiFERON-TB [Qiagen NV, Venlo, the Netherlands], and hepatitis and HIV serology) was undertaken. Meanwhile, because of considerable pruritus in the elbow and lower extremity regions, topical therapy was started with $\mathrm{Cal} / \mathrm{BD}$ aerosol foam.

After 2 weeks' application of $\mathrm{Cal} / \mathrm{BD}$ foam, a significant clinical response (PASI75) and an improvement of itching were attained (Figure 5B). The patient reported that $\mathrm{Cal} / \mathrm{BD}$ foam was easy and convenient to apply and was very satisfied with the clinical response particularly the fact that his itch had completely disappeared after a few days. Subsequently, 

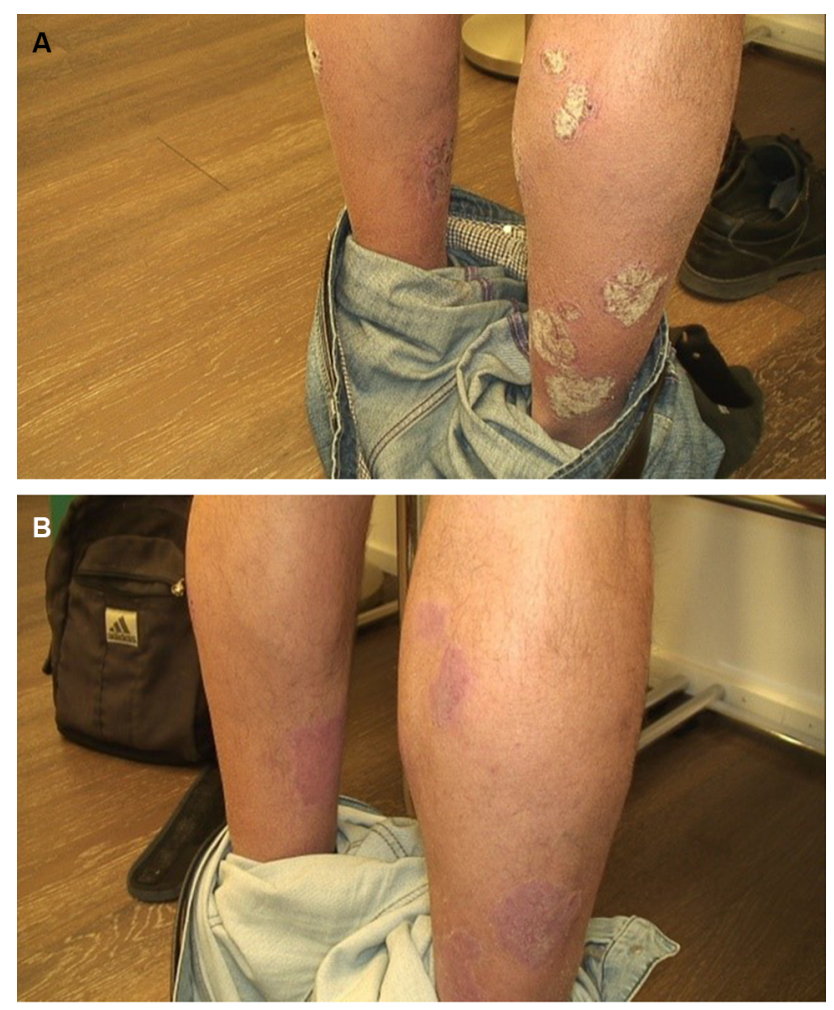

Figure 5 (A) Moderate-to-severe psoriasis in a 56-year-old male before treatment with Cal/BD aerosol foam. (B) Psoriatic lesion after 4 weeks' treatment with Cal/ BD aerosol foam.

Abbreviations: $\mathrm{BD}$, betamethasone dipropionate; Cal, calcipotriol.

after exclusion of tuberculosis, hepatitis, and HIV infection, biologic therapy was started and concurrent $\mathrm{Cal} / \mathrm{BD}$ aerosol foam was continued for a further 2 weeks.

\section{Discussion}

This review highlights RWE for a new aerosol foam formulation of $\mathrm{Cal} / \mathrm{BD}$ and demonstrates that this FDC preparation is markedly effective, and with high levels of patient satisfaction, in the following clinical settings:

1. Mild-to-moderate psoriasis, after previous inadequate efficacy of potent/very potent topical corticosteroids (even in combination with vitamin $\mathrm{D}_{3}$ analog).

2. Mild-to-moderate psoriasis, after a long history of previous insufficiently effective systemic therapy with acitretin, PUVA, and topical treatment.

3. Moderate psoriasis, after a prolonged history of previous inadequate efficacy of various topical corticosteroid treatments.

4. Moderate-to-severe psoriasis, after previous unsatisfactory therapy with oral methotrexate, and as a "bridge" to the introduction of biologic therapy.
A growing trend throughout dermatology and numerous other medical disciplines is for increasing reliance on RWE to facilitate more patient-centered approaches to treatment. RWE from case series and prospective registries endorses evidence obtained from randomized controlled trials (RCTs) Importantly, however, RWE studies can provide additional value in that they are conducted with daily-practice patients and treatment strategies that differ markedly from the strict conditions of RCTs. ${ }^{28-30}$

For $\mathrm{Cal} / \mathrm{BD}$ aerosol foam, RWE was recently obtained from a German multicenter, noninterventional study, in which 410 adults with psoriasis were observed for 4 weeks. ${ }^{31}$ The mean psoriasis duration was 15.3 years, the mean investigators' global assessment (IGA) of psoriasis severity was mild (IGA 2, 41.8\% of patients), moderate (IGA 3, 49.6\%), or severe (IGA $4,8.3 \%$ ), and $>80 \%$ of patients had used topical therapy before enrollment. A total of 390 patients were evaluated for efficacy, and $96.6 \%$ of them applied Cal/BD aerosol foam once daily. After 4 weeks application, $49.5 \%$ of patients had an IGA of "clear" or "almost clear" ( 0 or 1 , respectively). Efficacy was particularly marked in patients who had severe psoriasis (IGA 4) at baseline: after 4 weeks, $43.3 \%$ of these patients, compared with $24.3 \%$ of the total population, were clear or almost clear and had a $\geq 2$-step improvement in IGA. Overall, significant improvements were noted in mean BSA affected (from 12.9 to $7.6 \% ; P<0.0001$ ), mean IGA score (from 2.7 to $1.6 ; P<0.0001$ ), mean PASI score (from 10.4 to $5.2 ; P<0.0001$ ), and mean DLQI score (from 8.3 to $3.4 ; P<0.0001$ ), and $98.9 \%$ of investigators rated $\mathrm{Cal} / \mathrm{BD}$ tolerability as good or very good. Regarding patients' assessments after the first $\mathrm{Cal} / \mathrm{BD}$ application, approximately $70 \%$ of patients described the preparation as very or quite cooling and skin soothing, about $60 \%$ described it as very or quite itch-relieving, and about $90 \%$ described it as very or quite simple to handle. As early as 3 days after starting treatment, $16 \%$ of patients had a first visible improvement of psoriasis signs and $29 \%$ had their first 24 hours without itching; corresponding percentages at week 1 were 68 and $60 \%{ }^{31}$

Therefore, data from several sources - RCTs, ${ }^{23-26}$ case reports (as highlighted in this review), and RWE ${ }^{31}$ - underscore the considerable and rapid efficacy, effectiveness, and favorable safety and tolerability of $\mathrm{Cal} / \mathrm{BD}$ aerosol foam in psoriatic patients previously treated with class 3 or 4 topical corticosteroids, in patients unsatisfied with ongoing phototherapy with topical therapy, and in patients with moderateto-severe psoriasis. Besides these factors, patient preference for topical therapies is a significant issue, with potentially major influences on treatment adherence and HRQoL. Indeed, 
patient preference for a particular topical therapy may permit a more individualized approach to disease management so that patient acceptability can be optimized, long-term adherence enhanced, and treatment costs minimized. ${ }^{32-34}$

In the PSO-INSIGHTFUL study, ${ }^{34}$ a total of 213 adults with mild-to-severe psoriasis were randomized to 1 week's treatment with $\mathrm{Cal} / \mathrm{BD}$ aerosol foam or $\mathrm{Cal} / \mathrm{BD}$ gel. Total Product Usability Questionnaire (TPUQ) scores often significantly favored both $\mathrm{Cal} / \mathrm{BD}$ formulations relative to latest topical treatment (LTT; ie, patients' prestudy topical therapies). Significant $(P<0.01)$ advantages were evident for aerosol foam vs gel regarding immediate feeling of relief and felt soothing, and both the aerosol foam and gel were associated with significantly greater TPUQ satisfaction domain scores (confidence in using, would use regularly, and would recommend) and overall TPUQ satisfaction score than LTT. Vehicle Preference Measure (VPM) questionnaire scores revealed that younger patients (aged 18-39 years) tended to prefer the aerosol foam, whereas older patients ( $\geq 40$ years) tended to prefer the gel. VPM scores for both the aerosol foam and gel also tended to be greater in patients with more severe disease and thicker lesions. ${ }^{34}$

The PROPEL study, ${ }^{35}$ conducted in Canada, was essentially a larger version of the PSO-INSIGHTFUL trial, ${ }^{34}$ findings from which were consistent with earlier studies showing that patients with psoriasis generally preferred foams and solutions to other formulations. ${ }^{36-38}$ In PROPEL, among 449 patients with psoriasis, approximately half preferred the $\mathrm{Cal} / \mathrm{BD}$ aerosol foam formulation to their current topical treatment, and about $90 \%$ or more of respondents described the aerosol foam as appealing overall, easy to apply, quick to apply, and pleasant on the skin. Preference for the aerosol foam vehicle was especially marked relative to comparison with creams and ointments and in patients with poor disease control or severe disease. ${ }^{35}$

Given the relatively recent introduction of $\mathrm{Cal} / \mathrm{BD}$ aerosol foam, it is not surprising that in our case series, application of the formulation was started relatively late in each patient's clinical course. However, according to the rapid onset of clinical response including effectiveness against itch and considerable efficacy of $\mathrm{Cal} / \mathrm{BD}$ aerosol foam, in addition to its favorable safety and tolerability and high level of patient preference, it is highly likely that the foam preparation will continue to reinforce its central role in guidelines for the first-line topical treatment of mild-to-moderate psoriasis in adults (Figure 6).

Guideline-directed, first-line, topical treatment for any patient with psoriasis has an individualized aspect, such that treatment should be tailored to meet the specific health goals of the patient, and the need for treatment adherence to optimize outcomes should be emphasized. ${ }^{6,39}$ Key goals of newly started treatment in psoriasis are to significantly reduce PASI score (by $\geq 50 \%$ ) and improve HRQoL within 3-6 months; from a patient-centered standpoint, effective improvement of itching and confidence in treatment are also especially important. ${ }^{31,40}$ As outlined in this review, Cal/ BD aerosol foam demonstrated considerably reduced PASI scores, improved HRQoL, significantly reduced itching, and high levels of patient satisfaction with treatment in clinical trials and in RWE and case reports. ${ }^{5,21,24-26,31,34,35}$ Moreover, the aerosol foam formulation of $\mathrm{Cal} / \mathrm{BD}$ permits a state of supersaturation of the active constituents; this leads to enhanced skin penetration and local bioavailability of the constituents, together with enhanced efficacy relative to $\mathrm{Cal} /$ BD ointment and gel preparations. . $^{431,41}$

Particularly, important aspects of guideline-directed, firstline, topical therapy for psoriasis are the initial, fundamental considerations of patient preference, cosmetic acceptability, practical factors associated with treatment application, and BSA to be treated. ${ }^{6,39}$ For patients who fail to respond adequately to first-line topical therapy, topics to be discussed include possible difficulties with application, cosmetic acceptability, or tolerability and the opportunity for the use of an appropriate alternative formulation. ${ }^{39}$ These issues again underscore the value of $\mathrm{Cal} / \mathrm{BD}$ aerosol foam in providing such an alternative, with the potential for greater improvements in effectiveness, patient adherence, and HRQoL.

Our review has some limitations, the principal of which is the small number of cases reviewed $(n=5)$. There are also some limitations to the use of $\mathrm{Cal} / \mathrm{BD}$ aerosol foam: the need to educate/train patients to apply the product (distance and duration of spray); once-daily use is limited to 4 weeks, with patients instructed to use no more than 60 g every 4 days (median cost of a $60 \mathrm{~g}$ pack in Europe: $€ 51.84$ ); limited BSA during application $(<30 \%)$; it is not approved for use in children; and application may be difficult in small areas or on hairy scalp. However, the importance of RWE should not be overlooked, and it is interesting that our collection of cases outlined effectiveness for $\mathrm{Cal} / \mathrm{BD}$ aerosol foam across mild and moderate psoriasis, and as a bridge to biologic therapy in moderate-to-severe psoriasis. The latter finding concurs with other RWE, in which the initial mean BSA affected in patients treated with the aerosol foam was substantially greater than in corresponding RCTs (approximately 13 vs $7-8 \%)^{23,25,31}$ Long-term RWE data are now required about the use of $\mathrm{Cal} / \mathrm{BD}$ aerosol foam in everyday clinical practice, 


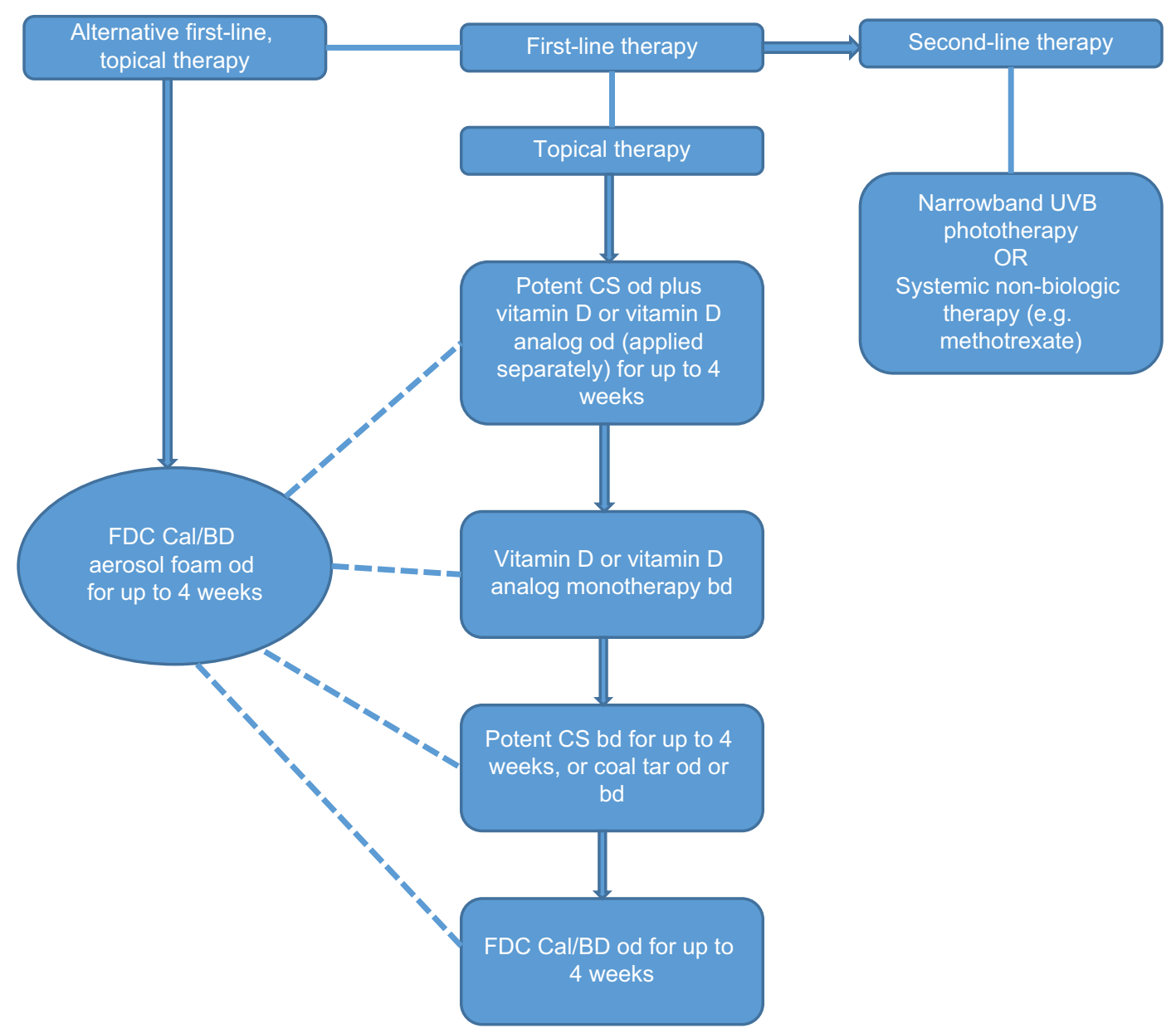

Figure 6 Simplified and suggested topical treatment algorithm for mild-to-moderate psoriasis affecting the trunk and limbs in adults. Abbreviations: bd, twice daily; BD, betamethasone dipropionate; Cal, calcipotriol; CS, corticosteroid; od, once daily.

and especially about whether a satisfactory response can be maintained beyond 4 weeks' treatment in patients with moderate-to-severe disease. ${ }^{31}$ Several ongoing clinical studies, including the Phase IV, PSO-REAL trial (ClinicalTrials. gov \# NCT02935582), which recruits patients with psoriasis in Sweden and the UK, and noninterventional studies being conducted in Spain, Italy, France, Austria, and Greece, will help to address this question.

\section{Conclusion}

The case reports discussed herein, considered together with other RWE, highlights that Cal/BD aerosol foam is effective and well tolerated in patients with a diverse range of psoriasis severity. This $\mathrm{Cal} / \mathrm{BD}$ formulation has a fast onset of effect, including rapid relief of itch-related symptoms, and is more effective and with greater levels of patient preference and acceptability than comparator preparations (including potent/ very potent corticosteroids). As such, $\mathrm{Cal} / \mathrm{BD}$ aerosol foam offers several treatment advantages and is an appropriate first-line topical therapy for consideration in patients with the psoriasis of any severity.

\section{Acknowledgments}

Medical writing support, under the direction of the authors, was provided by David P Figgitt, PhD, ISMPP CMPPTM, Content Ed Net (Germany), with funding from Leo Pharma $\mathrm{GmbH}$, Frankfurt, Germany. Funding for the case series described in this review article was provided by Leo Pharma $\mathrm{GmbH}$, Frankfurt, Germany.

\section{Disclosure}

Andreas Pinter has received honoraria as a speaker and for participating in Advisory Boards for Leo Pharma. Leo Pharma-sponsored clinical trials have been conducted at the 
University Hospital Frankfurt am Main, Germany. Ahmad Jalili and Henrik Thormann have received speaker and consultancy honoraria from Leo Pharma. The authors report no other conflicts of interest in this work.

\section{References}

1. Nestle FO, Kaplan DH, Barker J. Psoriasis. N Engl J Med. 2009;361(5): 496-509.

2. Lowes MA, Suárez-Fariñas M, Krueger JG. Immunology of psoriasis. Annu Rev Immunol. 2014;32:227-255.

3. Globe D, Bayliss MS, Harrison DJ. The impact of itch symptoms in psoriasis: results from physician interviews and patient focus groups. Health Qual Life Outcomes. 2009;7:62.

4. Paul C, Bang B, Lebwohl M. Fixed combination calcipotriol plus betamethasone dipropionate aerosol foam in the treatment of psoriasis vulgaris: rationale for development and clinical profile. Expert Opin Pharmacother. 2017;18(1):115-121.

5. Leonardi C, Bagel J, Yamauchi P, et al. The aerosol foam formulation of the fixed combination calcipotriene plus betamethasone dipropionate improves the health-related quality of life in patients with psoriasis vulgaris: Results from the randomized PSO-FAST study. $J$ Drugs Dermatol. 2016;15(8):981-987.

6. Menter A, Korman NJ, Elmets CA, et al. Guidelines of care for the management of psoriasis and psoriatic arthritis. Section 3. Guidelines of care for the management and treatment of psoriasis with topical therapies. J Am Acad Dermatol. 2009;60(4):643-659.

7. Uva L, Miguel D, Pinheiro C, et al. Mechanisms of action of topical corticosteroids in psoriasis. Int J Endocrinol. 2012;2012:561018.

8. Polistena B, Calzavara-Pinton P, Altomare G, et al. The impact of biologic therapy in chronic plaque psoriasis from a societal perspective: an analysis based on Italian actual clinical practice. J Eur Acad Dermatol Venereol. 2015;29(12):2411-2416.

9. Richard M-A, Corgibet F, Beylot-Barry M, et al. Sex- and age-adjusted prevalence estimates of five chronic inflammatory skin diseases in France: results of the "OBJECTIFS PEAU » study. J Eur Acade Dermatol Venereol. 2018;27.

10. Jungen D, Augustin M, Langenbruch A, et al. Cost-of-illness of psoriasis - results of a German cross-sectional study. J Eur Acad Dermatol Venereol. 2018;32(1):174-180.

11. Brezinski EA, Dhillon JS, Armstrong AW. Economic Burden of Psoriasis in the United States: A Systematic Review. JAMA Dermatol. 2015;151(6):651-658.

12. Levy AR, Davie AM, Brazier NC, et al. Economic burden of moderate to severe plaque psoriasis in Canada. Int $J$ Dermatol. 2012;51(12):1432-1440.

13. Patel NU, Felix K, Reimer D, Feldman SR. Calcipotriene/betamethasone dipropionate for the treatment of psoriasis vulgaris: an evidence-based review. Clin Cosmet Investig Dermatol. 2017;10:385-391.

14. Frieder J, Kivelevitch D, Menter A. Calcipotriene betamethasone dipropionate aerosol foam in the treatment of plaque psoriasis: a review of the literature. Ther Deliv. 2017;8(9):737-746.

15. Menter A, Gottlieb A, Feldman SR, et al. Guidelines of care for the management of psoriasis and psoriatic arthritis: Section 1. Overview of psoriasis and guidelines of care for the treatment of psoriasis with biologics. J Am Acad Dermatol. 2008;58(5):826-850.

16. Segaert $\mathrm{S}$, Ropke $\mathrm{M}$. The biological rationale for use of vitamin d analogs in combination with corticosteroids for the topical treatment of plaque psoriasis. J Drugs Dermatol. 2013;12(8):e129-e137.

17. Menter A, Korman NJ, Elmets CA, et al. Guidelines of care for the management of psoriasis and psoriatic arthritis: Section 5. Guidelines of care for the treatment of psoriasis with phototherapy and photochemotherapy. J Am Acad Dermatol. 2010;62(1):114-135.

18. Menter A, Korman NJ, Elmets CA, et al. Guidelines of care for the management of psoriasis and psoriatic arthritis: section 4. Guidelines of care for the management and treatment of psoriasis with traditional systemic agents. J Am Acad Dermatol. 2009;61(3):451-485.
19. Girolomoni G, Calzavara Pinton P, Cristaudo A, Cicchetti A. Back to the future: a new topical approach for mild-to-moderate psoriasis. $G$ Ital Dermatol Venereol. 2018;153(3):375-382.

20. Mason AR, Mason J, Cork M, et al. Topical treatments for chronic plaque psoriasis. Cochrane Database Syst Rev. 2013;28:CD005028.

21. Paul C, Leonardi C, Menter A, et al. Erratum to: Calcipotriol plus betamethasone dipropionate aerosol foam in patients with moderateto-severe psoriasis: Sub-group analysis of the PSO-ABLE study. Am J Clin Dermatol. 2017;18(4):591.

22. Queille-Roussel C, Olesen M, Villumsen J, Lacour JP. Efficacy of an innovative aerosol foam formulation of fixed combination calcipotriol plus betamethasone dipropionate in patients with psoriasis vulgaris. Clin Drug Investig. 2015;35(4):239-245.

23. Koo J, Tyring S, Werschler WP, et al. Superior efficacy of calcipotriene and betamethasone dipropionate aerosol foam versus ointment in patients with psoriasis vulgaris--A randomized phase II study. J Dermatolog Treat. 2016;27(2):120-127.

24. Paul C, Stein Gold L, Cambazard F, et al. Calcipotriol plus betamethasone dipropionate aerosol foam provides superior efficacy vs. gel in patients with psoriasis vulgaris: randomized, controlled PSO-ABLE study. J Eur Acad Dermatol Venereol. 2017;31(1):119-126.

25. Leonardi C, Bagel J, Yamauchi P, et al. Efficacy and Safety of Calcipotriene Plus Betamethasone Dipropionate Aerosol Foam in Patients With Psoriasis Vulgaris--a Randomized Phase III Study (PSO-FAST. J Drugs Dermatol. 2015;14(12):1468-1477.

26. Stein Gold L, Lebwohl M, Menter A, et al. Aerosol foam formulation of fixed combination calcipotriene plus betamethasone dipropionate is highly efficacious in patients with psoriasis vulgaris: pooled data from three randomized controlled studies. J Drugs Dermatol. 2016;15(8):951-957.

27. Kim ES, Frampton JE. Calcipotriol/betamethasone dipropionate foam: A review in plaque psoriasis. Drugs. 2016;76(15):1485-1492.

28. Zweegers J, Otero ME, van den Reek JM, et al. Effectiveness of biologic and conventional systemic therapies in adults with chronic plaque psoriasis in daily practice: A systematic review. Acta Derm Venereol. 2016;96(4):453-458.

29. Garcia-Doval I, Carretero G, Vanaclocha F, et al. Risk of serious adverse events associated with biologic and nonbiologic psoriasis systemic therapy: patients ineligible vs eligible for randomized controlled trials. Arch Dermatol. 2012;148(4):463-470.

30. Mason KJ, Barker J, Smith CH, et al. Comparison of drug discontinuation, effectiveness, and safety between clinical trial eligible and ineligible patients in BADBIR. JAMA Dermatol. 2018;154(5): 581-588.

31. Gerdes S, Krakor M, Anger T, Hutt HJ, Körber A. Prospective, Observational, Non-Interventional, Multicentre Study on the Efficacy and Tolerability of a New Calcipotriol/Betamethasone Aerosol Foam (Enstilarß) in Patients with Plaque Psoriasis under Daily Practice Conditions. Dermatology. 2017;233(6):425-434.

32. Svendsen MT, Andersen F, Hansen J, Johannessen H, Andersen KE. Medical adherence to topical corticosteroid preparations prescribed for psoriasis: A systematic review. J Dermatolog Treat. 2017;28(1):32-39.

33. Tan X, Feldman SR, Chang J, Balkrishnan R. Topical drug delivery systems in dermatology: a review of patient adherence issues. Expert Opin Drug Deliv. 2012;9(10):1263-1271.

34. Hong CH, Papp KA, Lophaven KW, Skallerup P, Philipp S. Patients with psoriasis have different preferences for topical therapy, highlighting the importance of individualized treatment approaches: randomized phase IIIb PSO-INSIGHTFUL study. J Eur Acad Dermatol Venereol. 2017;31(11):1876-1883.

35. Vender R, Gooderham MJ, Guenther LC, et al. Psoriasis patients' preference for an aerosol foam topical formulation. J Eur Acad Dermatol Venereol. 2018.

36. Housman TS, Mellen BG, Rapp SR, Fleischer AB, Feldman SR. Patients with psoriasis prefer solution and foam vehicles: a quantitative assessment of vehicle preference. Cutis. 2002;70(6):327-332.

37. Feldman SR, Housman TS. Patients' vehicle preference for corticosteroid treatments of scalp psoriasis. Am J Clin Dermatol. 2003;4(4):221-224. 
38. Stein L. Clinical studies of a new vehicle formulation for topical corticosteroids in the treatment of psoriasis. J Am Acad Dermatol. 2005;53(1 Suppl 1):S39-S49.

39. National Clinical Guideline Centre [webpage on the Internet]. Psoriasis. Management of Psoriasis. Clinical Guideline. Methods, Evidence and Recommendations. 2012. Available from. https://www.nice.org.uk/guidance/cg153/documents/psoriasis-full-guideline2. Accessed May 22, 2018.
40. Blome C, Gosau R, Radtke MA, et al. Patient-relevant treatment goals in psoriasis. Arch Dermatol Res. 2016;308(2):69-78.

41. Lind M, Nielsen KT, Schefe LH, et al. Supersaturation of calcipotriene and betamethasone dipropionate in a novel aerosol foam formulation for topical treatment of psoriasis provides enhanced bioavailability of the active ingredients. Dermatol Ther (Heidelb). 2016;6(3):413-425.

\section{Publish your work in this journal}

Clinical, Cosmetic and Investigational Dermatology is an international, peer-reviewed, open access, online journal that focuses on the latest clinical and experimental research in all aspects of skin disease and cosmetic interventions. This journal is included on PubMed. The manuscript management system is completely online and includes a very quick and fair peer-review system, which is all easy to use. Visit http://www.dovepress.com/testimonials.php to read real quotes from published authors

Submit your manuscript here: https://www.dovepress.com/clinical-cosmetic-and-investigational-dermatology-journal 